\title{
An increased risk of epithelial ovarian cancer in Taiwanese women with a new surgico-pathological diagnosis of endometriosis
}

Kuan-Chin Wang ${ }^{1 \dagger}$, Wen-Hsun Chang ${ }^{2,3,4,5 \dagger}$, Wen-Ling Lee ${ }^{1,3,6,7}$, Nicole Huang ${ }^{4}$, Hsin-Yi Huang ${ }^{8}$, Ming-Shyen Yen ${ }^{5,7}$, Chao-Yu Guo ${ }^{4,11^{*}}$ and Peng-Hui Wang $3,5,7,9,10,11^{*}$

\begin{abstract}
Background: Epidemiological evidence of relationships between endometriosis and epithelial ovarian cancer (EOC) has been obtained mainly from Western countries. Our goal was to determine the risk of EOC due to endometriosis in Taiwanese women.

Methods: A retrospective cohort study was performed by linking to the National Health Insurance Research Database (NHIRD) of Taiwan. A total of 5,945 women with a new surgico-pathological diagnosis of endometriosis from 2000 to 2010 and 23,780 multivariable-matched controls (1:4) were selected. The Cox regression model adjusted for potential confounders was used to assess the risk of EOC due to endometriosis.

Results: The EOC incidence rate (IR) of the women with and without endometriosis was 11.64 and 2.66 per 10,000 person-years, contributing to a crude hazard ratio (HR) of 4.48 (95\% confidence interval [Cl] 2.84-7.06), and HR after adjustment for all confounders (adjusted HR) of 5.62 (95\% Cl 3.46-9.14); the risk was higher in clear-cell carcinoma subtypes (adjusted HR 7.36, 95\% Cl 1.91-28.33). The EOC IR of women with endometriosis consistently increased with increasing age, ranging from 4.99 ( $<30$ years) to 35.81 ( $\geq 50$ years) per 10,000 person-years, contributing to a progressively increased risk of EOC (crude HRs ranging from 2.80 to 6.74 and adjusted HRs ranging from 3.34 to 9.63) compared to age-matched women without endometriosis, whose EOC IR also increased with age. The older women ( $\geq 50$ years) with endometriosis had a risk of EOC that was higher than both the age-matched women without endometriosis (adjusted HR 9.63, 95\% Cl 3.27-28.37) and the youngest women ( $<30$ years) with endometriosis (adjusted HR 4.97, 95\% Cl 1.03-24.09).

Conclusions: These significant findings corroborate the previously reported association between endometriosis and increased risk of EOC. Since the risk of EOC in women with a new surgico-pathological diagnosis of endometriosis constantly increased with age and this increased risk of EOC was more significant in women aged $\geq 50$ years, active and intensive surgical intervention should be taken into consideration for older women with endometriosis.
\end{abstract}

Keywords: Cohort study, Endometriosis, Epidemiology, Epithelial ovarian cancer

\footnotetext{
* Correspondence: cyguo@ym.edu.tw; phwang@vghtpe.gov.tw

${ }^{\dagger}$ Equal contributors

${ }^{4}$ Institute of Public Health, and Institute of Hospital and Health Care

Administration, National Yang-Ming University, Taipei, Taiwan

${ }^{3}$ Department of Nursing, National Yang-Ming University School of Nursing,

Taipei, Taiwan

Full list of author information is available at the end of the article
}

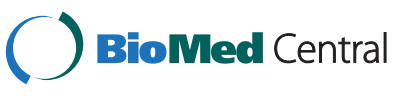

(c) 2014 Wang et al.; licensee BioMed Central Ltd. This is an Open Access article distributed under the terms of the Creative Commons Attribution License (http://creativecommons.org/licenses/by/4.0), which permits unrestricted use, distribution, and reproduction in any medium, provided the original work is properly credited. The Creative Commons Public Domain Dedication waiver (http://creativecommons.org/publicdomain/zero/1.0/) applies to the data made available in this article, unless otherwise stated. 


\section{Background}

Many epidemiologic studies have supported the finding that women with endometriosis may have an increased risk of developing and/or being associated with epithelial ovarian cancers (EOCs) [1-23]. However, nearly all evidence has been obtained from Western countries [3-25]. A recent meta-analysis by Kim and colleagues investigating the impact of endometriosis on the risk and prognosis of ovarian cancer concluded that endometriosis is strongly associated with an increased of ovarian cancer but endometriosis may not affect disease progression after the onset of ovarian cancer [25]. However, the risk ratio (RR) was only 1.27 (95\% confidence interval [CI] $=1.21-1.32)$ in case-control or two-arm cohort studies and the standard incidence ratio (SIR) was 1.80 (95\% CI 1.28-2.53), respectively [25]. The RR of "endometriosisassociated EOC", including endometrioid and clear-cell subtypes of EOC in women with endometriosis, was 1.76 (95\% CI 1.55-2.00) and 2.61 (95\% CI 2.23-3.05), respectively [25].

Except the strong association between the clear-cell subtype and EOC, all others seemed to be well under the level that supports causality. Why did the data show only a weak association between endometriosis and EOC? Although it is difficult to respond to the above question, a possible reason might be the heterogeneity within the newly defined population, since clinical heterogeneity, when present, has implications for the design of research studies [26-28]. For example, Buis and colleagues found that an increased risk was found in women with endometriosis when the definition of endometriosis was based on self-report, medical records information at subfertility treatment and/or a nationwide pathology database (HR 8.2, 95\% CI 3.1-21.6) [22]. The risk was especially high in women with pathologicallyconfirmed endometriosis after subfertility treatment, with a HR of 12.4 (95\% CI 2.8-54.2) [22]. In addition, previous studies might have been influenced by any one or more of many factors, such as age, obstetric and gynecologic history (nulliparity, menstrual cycles, infertility status, pelvic inflammatory disease [PID], or hysterectomy history, the use of pills and tubal ligation) and many chronic illnesses - such as cardiovascular disease (CVD), diabetes mellitus (DM), chronic liver disease (CLD), and rheumatic disease (RD), that might contribute to the estimation of cancer risk $[14,20]$. And, to avoid surveillance bias for cancer, which may shorten the time to cancer diagnosis and cause over-estimation of risks, most studies excluded synchronous cases (defined as having a time interval between the detection of endometriosis and EOC of 6 to 12 months), resulting in an under-estimation of the association. The aim of this study was to investigate whether endometriosis was really associated with EOC after adjusting the above- mentioned factors. In order to achieve our aim, we conducted a large-scale, nationwide, controlled cohort study.

\section{Methods}

The source population consisted of nearly the entire population of Taiwan (23 million inhabitants) and the data was that of the research database of the Taiwanese National Health Insurance (NHI) program from 1996 to 2010. The Longitudinal Health Insurance Database 2000 (LHID 2000) contains 1 million randomly sampled beneficiaries. The data of the sampled subjects in the LHID 2000 are representative of all beneficiaries with regard to age, sex, and insurance cost, which have been described in detail before $[29,30]$.

This was a retrospective cohort study. According to the written operating procedures, Good Clinical Practice (GCP), and the applicable regulatory requirements, this study projected was approved by the Institutional Review Board of Taipei Veterans General Hospital (Chairman, Professor Shung-Tai Ho, VGHIRB No.: 2012-12-012BC), and the board is organized under, and operates according to International Conference on Harmonisation (ICH)/ WHO GCP and the applicable laws and regulations. The National Health Research Institute in Taiwan permitted the access to the data in the National Health Insurance Research Database, and 29,725 women aged between 20 and 51 years were identified. Women without a visit to an obstetrician or gynecologist during the study period were excluded. In order to increase the validity of identifying women with newly diagnosed endometriosis in the administrative data set, only those women with a new surgico-pathological diagnosis of endometriosis (International Classification of Diseases, Ninth Revision, and Clinical Modifications [ICD9-CM] code 617), regardless of clinical diagnosis of endometriosis status, during the period between January 1, 2000 and December 31, 2010 were included among the incident endometriosis women $(n=5,945)$.

To validate the surgico-pathological diagnosis of endometriosis, surgical treatments for endometriosis especially limited to the ovary, tube, and peritoneal cavity were also recorded. These included laparoscopy (ICD9-CM codes 54.21) and laparoscopic surgery, such as laparoscopic lysis of peritoneal adhesions (54.51), laparoscopic oophorectomy (65.01), laparoscopic diagnostic procedures related to the ovaries (65.13 and 65.14), laparoscopic local excision or destruction of the ovaries (65.23, 65.24, and 65.25), laparoscopic unilateral oophorectomy (65.31), laparoscopic unilateral salpingo-oophorectomy (65.41), laparoscopic salpingo-oophoroplasty (65.76), and laparoscopic lysis of adhesions to the ovary and fallopian tube (65.81). Exploratory laparotomy, such as lysis of peritoneal adhesions (54.59), oophorectomy (65.0), aspiration biopsy of the ovary (65.11 and 65.12), local excision or destruction 
of the ovary $(65.21,65.22$, and 65.29), unilateral oophorectomy (65.3), unilateral salpingo-oophorectomy (65.49), salpingo-oophoroplasty (65.73), and lysis of adhesions to the ovary and fallopian tube (65.89), was also included. However, to decrease the influence of hysterectomy, bilateral salpingo-oophorectomy, and bilateral oophorectomy on the development of future EOC, women with hysterectomy, except those women with a diagnosis of invasive EOC during the follow-up period, were excluded.

Each endometriosis case was matched with 4 female controls by age, index year, obstetric history, frequency of gynecological/obstetric providers' outpatient visits, contraception methods, socioeconomic status, work and urbanization, which resulted in an overall sample size of 23,780 matched controls without endometriosis (Figure 1). For the women with endometriosis, the index date was the date of a new surgico-pathological diagnosis of endometriosis. For the controls, the index date was the first visit to an obstetric/gynecological provider or admission during the study period.

EOC was initially detected using inpatients with a surgico-pathological diagnosis and validated using the major disease files (ICD-9-CM 183) from the Registry for Catastrophic Illness Patients.

Starting from the cohort index date, the study subjects were followed until hospitalization with EOC or to the end of the study (December 31, 2010), whichever came first, if no EOC had occurred. The specific histologic subtype distribution of EOC in women with and without endometriosis came from the database of the National Cancer Registration System [31]. The histological types used were based on the World Health Organization Classification of Tumors [32], and included serous (8441/3, $8460 / 3,8461 / 3)$, mucinous $(8470 / 2,8470 / 3,8471 / 3,8480 /$ $3,8482 / 3)$, endometrioid $(8380 / 3,8382 / 3,8383 / 3)$, clear cell $(8310 / 3,8313 / 3)$, malignant Brenner (9000/3), undifferentiated (8020/3, 8021/3), and carcinosarcoma (8950/3, 8980/3, 8981/3). "Endometriosis-associated" EOCs, including clear-cell and endometrioid-cell types, were reported to be highly associated with endometriosis [10,17,23-25]. Patients without an EOC event were treated as censored subjects. Dropouts or those who were lost to follow-up were also treated as censored. Basic characteristics are presented as percentages. The incidence of EOC was compared between the women with and without endometriosis using the incidence rate (IR). The $\chi^{2}$ test was used to compare the IR estimates of invasive EOC among subsamples. The Cox proportional hazards model was used to calculate the HR and 95\% CI to determine whether newly diagnosed endometriosis is a risk factor for EOC.

In order to handle the issue of matching, the robust sandwich estimate of Lin and Wei [33] for the covariance

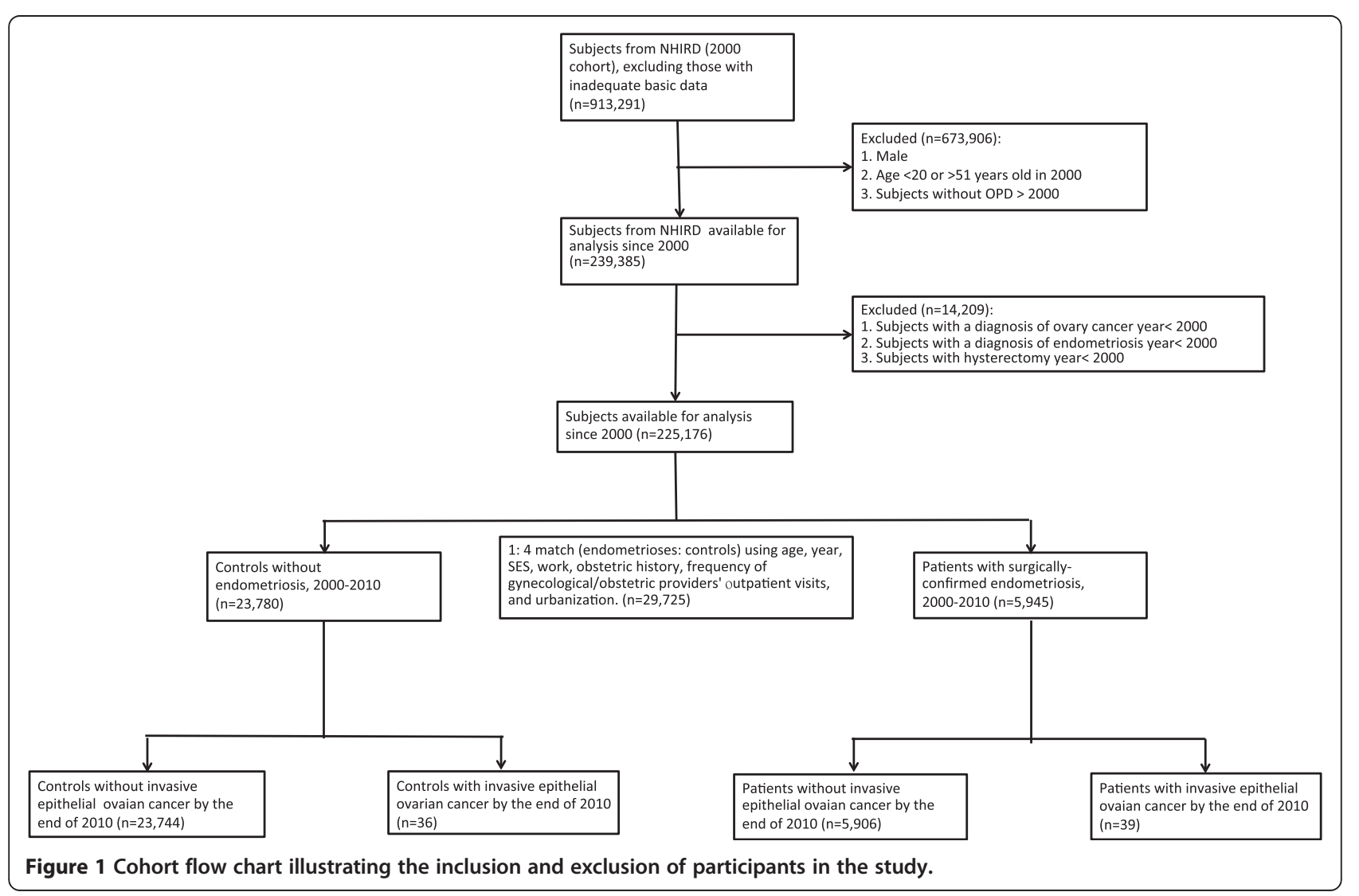


matrix was used in the Wald tests to test the global null hypothesis and null hypotheses of individual parameters. Variables adjusted in the Cox model were PID, infertility status, CVD, DM, CLD and RD. Statistical analyses were implemented with SAS version 9.3 (SAS Institute Inc., Cary, North Carolina, USA), STATA version 10.0 (STATA Corp, College Station, Texas, USA), and SPSS version 20 (SPSS, Chicago, IL, USA).

\section{Results}

Seventy-five of the total 29,725 women had EOC between 2000 and 2010. The total person-years of follow-up were 168,927 , including 33,519 for the women with a surgicopathological diagnosis of endometriosis and 135,408 for the women without endometriosis. The women with endometriosis had higher rates of comorbid PID, infertility, CVD, DM, CLD, and RD than did the women without endometriosis (all $p<0.0005)$ (Table 1 ).

The EOC IR of the women with and without a surgico-pathological diagnosis of endometriosis was 11.64 and 2.66 per 10,000 person-years, respectively, contributing to a crude HR of 4.48 (95\% CI 2.84-7.06), and $\mathrm{HR}$ after adjustment for confounders (adjusted HR) of 5.62 (95\% CI 3.46-9.14) (Table 2).

In an effort to clarify the role of age in the relationship between endometriosis and EOC, we performed subgroup analysis based on age, using 4 age groups (those $<30,30-39,40-49$, and $\geq 50$ years). The median age of the women with and without endometriosis who had a diagnosis of EOC was 43.6 and 43.3 years, respectively, which was without statistical significance $(p=0.8783)$. The risks of EOC in the women with endometriosis increased with increasing age. The EOC IR of the women with endometriosis ranged from the lowest IR of 4.99 per 10,000 person-years at age $<30$ years to the highest IR of 35.81 at age $\geq 50$ years (Table 3 ). Using the youngest group (women $<30$ years) as the reference, the HRs (95\% CI) of the women with endometriosis aged 30-39, 40-49, and $\geq 50$ years were 1.74 (95\% CI 0.38-7.96), 1.87 (95\% CI $0.43-8.01$ ), and 5.46 (95\% CI 1.18-25.32), respectively, in the crude model $(p=0.0223)$. After adjustment for confounders, the adjusted HRs $(95 \% \mathrm{CI})$ of women with endometriosis aged 30-39, 40-49, and $\geq 50$ years were 1.66 (95\% CI 0.36-7.61), 1.70 (95\% CI 0.38-7.59), and 4.97 (95\% CI 1.03-24.09), respectively ( $p=0.0351)$. Both analyses revealed a risk of EOC in the women with endometriosis that significantly increased with age (Table 3 ).

The risk of EOC in the women without endometriosis also increased with age (IR of EOC in this population ranged from 1.78 to 5.80 per 10,000 person-years in all age groups), except those women aged between 30 and 39 years-it decreased in this group. In spite of an increased EOC IR with increasing age in the women without endometriosis, the women with endometriosis still had a more progressively increased risk of EOC with increasing age than the women without endometriosis (crude HRs ranging from 2.80 to 6.74 and adjusted HRs ranging from 3.34 to 9.63) (Table 4). Both the crude $(p=0.0015)$ and adjusted $(p=0.0039)$ Cox models were statistically significant. Our results suggested that age was an important risk factor for EOC in women with endometriosis, since older women with endometriosis not only had the absolute highest risk of EOC (35.81 per 10,000 person-years of EOC IR), but also had a more significantly increased risk of EOC than younger women with endometriosis, with a HR of 4.97 (95\% CI 1.03-24.09).

The role of follow-up time between enrollment and the occurrence of EOC (interval) was investigated. The median interval between the cohort index date and the date of a surgico-pathological diagnosis of EOC for the women with and without endometriosis was 505 days (ranging from 5 to 3433 days) and 824 days (ranging from 1 to 4095 days), respectively. There was a statistically significant difference between the 2 groups $(p=0.0396)$, suggesting that women with endometriosis had a statistically significantly shorter interval in which to get EOC than women without endometriosis did. In fact, the highest risk of EOC was found in the first-year follow-up. The increased risk of EOC in the women with endometriosis remained consistent and persistent, since they had a significantly higher risk of EOC than the women without during the subsequent follow-up period $(\geq$ one-year follow-up), with an adjusted HR of 3.32 (95\% CI 1.486.68), after excluding the EOC cases in the first year of follow-up. All of this suggested that the women with endometriosis really did have a higher risk of EOC than the women without (Figure 2).

The median follow-up time for the women with and without endometriosis was similar, and without a statistically significant difference (2059 days, ranging from 3 to 4019 days vs. 2080 days, ranging from 1 to 5243 days, respectively, $p=0.2267$ ). Furthermore, there was no statistically significant difference in the median visits to gynecologists between the 2 groups (8.9, ranging from 6 to 77 visits vs. 9.1, ranging from 6 to 77 visits, for the women with and without endometriosis, respectively, $p=0.6881$ ). We separated the follow-up intervals into one and 2 years to test the IR of EOC in each group, and found that the EOC IR of the women with endometriosis was always higher than that of the women without, contributing to a consistently and persistently higher risk of EOC in the women with endometriosis than that in the women without, regardless of the interval of followup $(p=1.000)$.

Finally, we investigated whether the increased risk of EOC in women with endometriosis might be influenced by the significantly increasing incidence of "endometriosis- 
Table 1 Baseline characteristics of the study subjects

\begin{tabular}{|c|c|c|c|c|c|c|c|}
\hline \multirow{3}{*}{$\begin{array}{l}\text { Person-years } \\
\text { Variable }\end{array}$} & \multirow{2}{*}{\multicolumn{2}{|c|}{$\begin{array}{c}\text { Total }(n=29725) \\
168927\end{array}$}} & \multirow{2}{*}{\multicolumn{2}{|c|}{$\begin{array}{l}\text { Endometriosis patients }(n=5945) \\
\qquad 33519\end{array}$}} & \multirow{2}{*}{\multicolumn{2}{|c|}{$\begin{array}{c}\text { Controls }(n=23780) \\
135408\end{array}$}} & \multirow[t]{3}{*}{ P-value } \\
\hline & & & & & & & \\
\hline & $\mathbf{n}$ & $\%$ & $\mathbf{n}$ & $\%$ & $\mathrm{n}$ & $\%$ & \\
\hline Catastrophic illness & & & & & & & $<0.0001$ \\
\hline EOC & 75 & 0.25 & 39 & 0.66 & 36 & 0.15 & \\
\hline No EOC & 29650 & 99.75 & 5906 & 99.34 & 23744 & 99.85 & \\
\hline Age $^{*}$ & & & & & & & 0.0750 \\
\hline$\leq 41$ & 14877 & 50.05 & 2914 & 49.02 & 11963 & 50.31 & \\
\hline$e>41$ & 14848 & 49.95 & 3031 & 50.98 & 11817 & 49.69 & \\
\hline SES & & & & & & & 0.8868 \\
\hline$\geq 40000$ & 4579 & 15.40 & 911 & 15.32 & 3668 & 15.42 & \\
\hline 20000-39999 & 9790 & 32.94 & 1941 & 32.65 & 7849 & 33.01 & \\
\hline$<20000$ & 10236 & 34.44 & 2073 & 34.87 & 8163 & 34.33 & \\
\hline Others & 5120 & 17.22 & 1020 & 17.16 & 4100 & 17.24 & \\
\hline Work & & & & & & & 0.5954 \\
\hline Yes & 27617 & 92.91 & 5514 & 92.75 & 22103 & 92.95 & \\
\hline No & 2108 & 7.09 & 431 & 7.25 & 1677 & 7.05 & \\
\hline Urbanization & & & & & & & 0.9752 \\
\hline Urban & 9957 & 33.50 & 1991 & 33.49 & 7966 & 33.50 & \\
\hline Suburban & 12549 & 42.22 & 2504 & 42.12 & 10045 & 42.24 & \\
\hline Rural & 7219 & 24.29 & 1450 & 24.39 & 5769 & 24.26 & \\
\hline PID & & & & & & & $<0.0001$ \\
\hline Yes & 13647 & 45.91 & 4518 & 76.00 & 9129 & 38.39 & \\
\hline No & 16078 & 54.09 & 1427 & 24.00 & 14651 & 61.61 & \\
\hline Infertility & & & & & & & $<0.0001$ \\
\hline Yes & 1094 & 3.68 & 608 & 10.23 & 486 & 2.04 & \\
\hline No & 28631 & 96.32 & 5337 & 89.77 & 23294 & 97.96 & \\
\hline CV disease & & & & & & & $<0.0001$ \\
\hline Yes & 1133 & 3.81 & 290 & 4.88 & 843 & 3.54 & \\
\hline No & 28592 & 96.19 & 5655 & 95.12 & 22937 & 96.46 & \\
\hline Diabetes mellitus & & & & & & & $<0.0001$ \\
\hline Yes & 1820 & 6.12 & 448 & 7.54 & 1372 & 5.77 & \\
\hline No & 27905 & 93.88 & 5497 & 92.46 & 22408 & 94.23 & \\
\hline Chronic liver disease & & & & & & & 0.0002 \\
\hline Yes & 477 & 1.60 & 128 & 2.15 & 349 & 1.47 & \\
\hline No & 29248 & 98.40 & 5817 & 97.85 & 23431 & 98.53 & \\
\hline Rheumatic disease & & & & & & & $<0.0001$ \\
\hline Yes & 796 & 2.68 & 235 & 3.95 & 561 & 2.36 & \\
\hline No & 28929 & 97.32 & 5710 & 96.05 & 23219 & 97.64 & \\
\hline
\end{tabular}

EOC: invasive epithelial ovarian cancer; SES: socio-economic status; PID: pelvic inflammatory disease; CV disease: cardiovascular disease.

*Age variable was matched by the exact year of age, but the table shows age quartile groups. The median age of women with and without endometriosis was 40.5 and 40.4 years of age, respectively $(p=0.3570)$.

associated EOC", such as endometrioid and clear-cell subtypes [34-37]. As expected, women with endometriosis had a higher risk of "endometriosis-associated" EOC (adjusted HR 3.70, 95\% CI 1.62-8.46), and the risk of clear-cell subtypes was much increased (adjusted HR 7.36, 95\% CI 1.91-28.33). By contrast, other cell-type EOCs might not be associated with endometriosis, since there was no statistically significant difference between the women 
Table 2 Incidence and crude and adjusted risk of invasive epithelial ovarian cancer, according to endometriosis status

\begin{tabular}{lcc}
\hline & $\begin{array}{c}\text { Patients with } \\
\text { endometriosis }(\boldsymbol{n}=\mathbf{5 9 4 5})\end{array}$ & $\begin{array}{c}\text { Controls } \\
(\boldsymbol{n}=\mathbf{2 3 7 8 0})\end{array}$ \\
\hline Number of patients with EOC & 39 & 36 \\
Incidence per 10,000 & 11.64 & 2.66 \\
person-years & & 1.00 \\
Crude HR (95\% Cl) & $4.48(2.84-7.06)^{*}$ & 1.00 \\
Adjusted HR (95\% Cl) & $5.62(3.46-9.14)^{*}$ &
\end{tabular}

EOC: invasive epithelial ovarian cancer; HR: hazard ratio; $95 \% \mathrm{Cl}: 95 \%$ confidence interval.

Adjusted for pelvic inflammatory disease, infertility status, cardiovascular disease, diabetes mellitus, chronic liver disease, and rheumatic disease. ${ }^{*} \mathrm{P}<0.001$

with and without endometriosis (adjusted HR 0.948, 95\% CI 0.27-3.28).

\section{Discussion}

Although many studies have supported the positive association between endometriosis and EOC, many uncertainties remain. One is the very low risk of developing EOC from endometriosis, estimated at a $<1.5 \%$ lifetime probability, compared with $1 \%$ in the general female population [38]. In addition, co-morbidities of endometriosis, such as primary infertility, seemed more likely to carry a risk of EOC [20]. Many infertility studies have shown no association between endometriosis and EOC $[18,21]$. Furthermore, contraception methods (tubal ligation, oral pills, etc.), especially the use of oral pills, which might be prescribed for treating symptoms of endometriosis, are inversely related to the risk of EOC $[14,39]$. Finally, hysterectomy and/or bilateral salpingooophorectomy might have a protective effect on the occurrence of EOC $[23,35]$. The strength of this study was that surgical confounders, such as tubal ligation, hysterectomy, and bilateral salpingo-oophorectomy were well controlled, because they had been excluded in this study.

This study has another important strength, that is, it might be the first nationwide, population-based study in an Asian country. One study was conducted in Japan, but it might not be representative of the general population of women with "endometriosis" in Asia [1]. In the Japan study [1], the diagnosis of "endometriosis" was made by ultrasound, the disease was limited to the ovary, and only $1 / 3$ of cases had surgical confirmation. In our study, all subjects with endometriosis were found in an administrative data set, and all of the women had a new surgico-pathological confirmation, including nearly half who were diagnosed as having ovarian endometrioma (data not shown). Buis and colleagues found that the increased risk was especially high in women with pathologically-confirmed endometriosis after subfertility treatment, with an HR of 12.4 (95\% CI 2.8-54.2), compared with an HR of 8.2 (95\% CI 3.1-21.6) in women whose endometriosis was diagnosed by self-report or medical record information at subfertility treatment and/or in the nationwide pathology database [22], suggesting that a bias of selected subjects for either the study group or the control group might significantly influence the risk estimation. Although the strict criterion of "a surgico-pathological diagnosis" of endometriosis might exaggerate the incidence rate of EOC in the endometriosis arm of the study, with a subsequently inflated risk of EOC in this arm, the risk of EOC in women with endometriosis in the current study was still far lower than in Buis and colleagues' report (HR 5.62 vs. HR 12.4). In addition, Melin and colleagues [11] showed that women who underwent unilateral oophorectomy for endometriosis or radical surgical excision of all visible endometriosis had a significantly reduced risk of later development of EOC, with adjusted odds ratios of 0.19 (95\% CI, 0.08-0.46) and 0.30 (95\% CI, 0.12-0.74), respectively, compared with controls. In our current study, we did not analyze the effect of different surgical procedures in the management of endometriosis, and we believe that some of the women may have been treated with unilateral salpingo-oophorectomy or radical surgical excision, which might be a protective procedure against the occurrence of EOC, but we still found that those women with a new surgico-pathological diagnosis of endometriosis had a persistently and consistently higher risk of later development of EOC during the follow up in the current study. Finally, after adjustment of

Table 3 An increased risk of epithelial ovarian cancer in women with endometriosis with age

\begin{tabular}{|c|c|c|c|c|c|}
\hline & $\begin{array}{c}\text { Age }<30 \text { years } \\
n=573\end{array}$ & $\begin{array}{c}\text { Age 30-39 years } \\
n=1791\end{array}$ & $\begin{array}{c}\text { Age } 40-49 \text { years } \\
n=3023\end{array}$ & $\begin{array}{c}\text { Age } \geq 50 \text { years } \\
n=558\end{array}$ & $P^{*}$ \\
\hline$\overline{\mathrm{IR}}$ & 4.99 & 9.89 & 10.66 & 35.81 & \\
\hline Crude HR (95\% Cl) & 1.00 (Reference) & $1.74(0.38-7.96)$ & $1.87(0.43-8.05)$ & $5.46(1.18-25.32)$ & 0.0223 \\
\hline$P^{* *}$ & & 0.4729 & 0.4022 & 0.0302 & \\
\hline Adjusted HR (95\% Cl) & 1.00 (Reference) & $1.66(0.36-7.61)$ & $1.70(0.38-7.59)$ & $4.97(1.03-24.09)$ & 0.0351 \\
\hline$P^{* *}$ & & 0.5154 & 0.4853 & 0.0465 & \\
\hline
\end{tabular}

IR: incidence rate (incidence per 10,000 person-years); HR: hazard ratio; *P: comparison among all groups. ${ }^{* *}$ p: comparison between study group and reference group (age $<30$ years). 
Table 4 Incidence and crude and adjusted risk of invasive epithelial ovarian cancer, according to age

\begin{tabular}{|c|c|c|c|c|c|c|c|c|}
\hline & \multicolumn{2}{|c|}{ Age $<30$ years $(n=3148)$} & \multicolumn{2}{|c|}{ Age $30-39$ years $(n=9310)$} & \multicolumn{2}{|c|}{ Age $40-49$ years $(n=13747)$} & \multicolumn{2}{|c|}{ Age $\geq 50$ years $(n=3520)$} \\
\hline & Patients & Controls & Patients & Controls & Patients & Controls & Patients & Controls \\
\hline \multicolumn{9}{|l|}{ Diagnosis of EOC } \\
\hline Yes & 2 & 3 & 10 & 4 & 18 & 22 & 9 & 7 \\
\hline No & 571 & 2572 & 1781 & 7515 & 3005 & 10702 & 549 & 2955 \\
\hline IR & 4.99 & 1.78 & 9.89 & 0.96 & 10.66 & 3.38 & 35.81 & 5.80 \\
\hline Crude HR $(95 \%$ Cl) & $2.80(0.47-16.74)$ & 1.00 & $13.80(3.80-50.11)^{* *}$ & 1.00 & $3.03(1.62-5.64)^{*}$ & 1.00 & $6.74(2.51-18.10)^{*}$ & 1.00 \\
\hline Adjusted HR (95\% Cl) & $3.34(0.54-20.60)$ & 1.00 & $19.41(5.02-75.10)^{* *}$ & 1.00 & $3.41(1.76-6.61)^{*}$ & 1.00 & $9.63(3.27-28.37)^{* *}$ & 1.00 \\
\hline
\end{tabular}

Patients: women with endometriosis; Controls: women without endometriosis; EOC: epithelial ovarian cancer; IR: incidence rate (incidence per 10,000 person-years); HR: hazard ratio; $\mathrm{Cl}$ : confidence interval; ${ }^{*} \mathrm{P}<0.001,{ }^{* *} \mathrm{P}<0.0001$.

confounding factors, the women with endometriosis had a much higher risk of EOC than the women without (adjusted HR 5.62, 95\% CI 3.46-9.14 vs. crude HR 4.48, 95\% CI 2.84-7.06), suggesting that women with a new surgico-pathological diagnosis of endometriosis indeed have a higher risk of EOC than women without.

The other argument, that the highest proportion of EOC was diagnosed in the first year of follow-up, including 29 of the 39 EOCs in the women with a new surgico-pathological diagnosis of endometriosis and 22 of the 36 EOCs in the women without, contributing to an unusually high IR of EOC in both groups, was raised. Furthermore, the some of the women had a diagnosis of EOC immediately within the enrolment period. Twentyfour and fifteen patients with EOC were found in the women with and without a new surgico-pathological diagnosis of endometriosis, respectively $(p=0.0853)$, if we defined that the enrolment period was less than 90 days. An additional argument was that all women with endometriosis had a surgery, but not all of the controls did. It is possible that the women underwent surgery for a clinical diagnosis of endometriosis but were found to have cancer, resulting in more EOC patients in the endometriosis arm being detected. The number of cases of endometriosis was a quarter of cases in the women without endometriosis and every change by one case in the incidence (cancer) of women with a new surgico-pathological diagnosis of endometriosis would exaggerate the incidence ratio fourfold. All of this emphasized the potential risk of biases secondary to surveillance, including surgery, symptoms, and frequency of gynecologist/obstetrician visits in our current study.

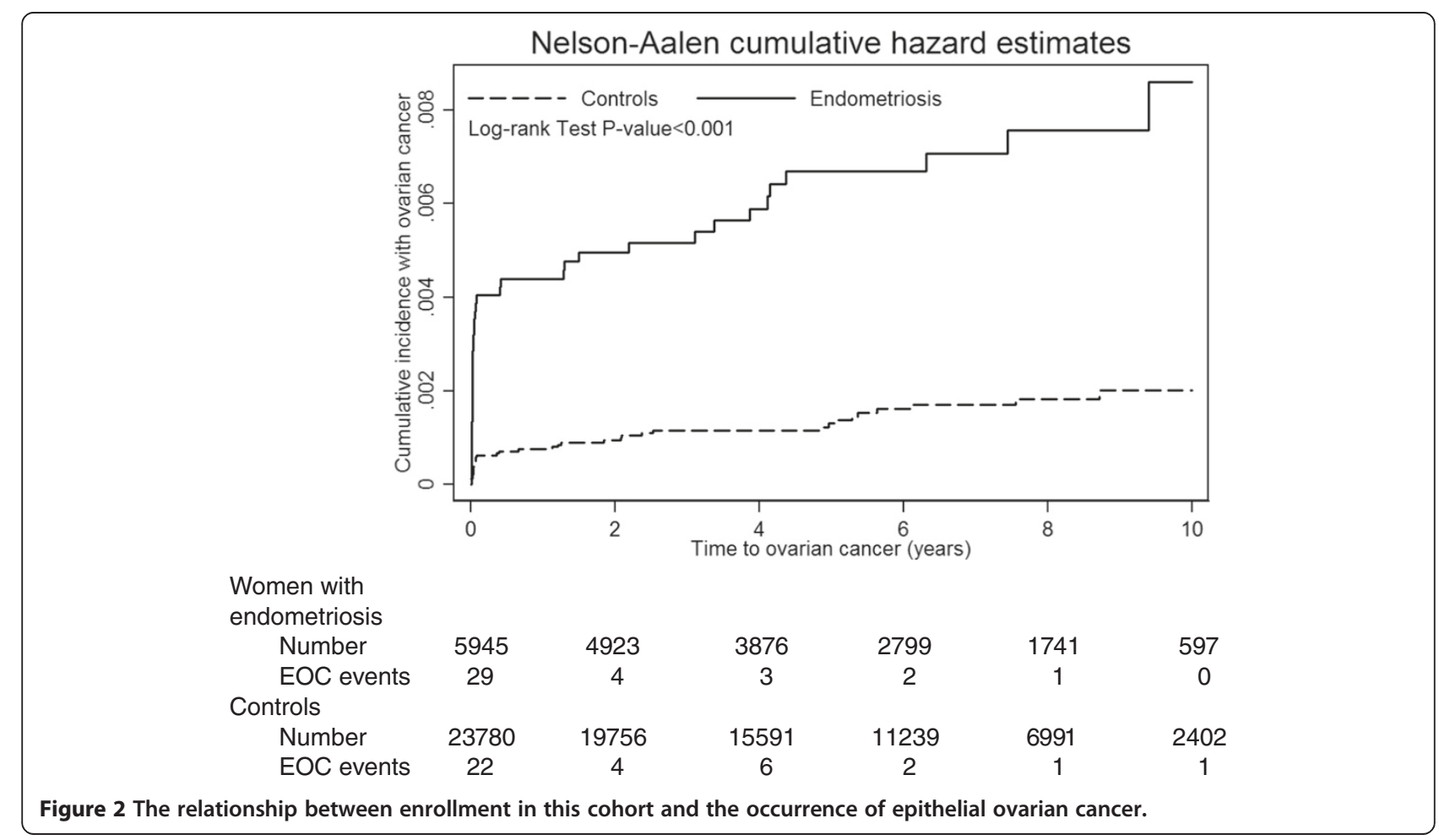


They are worthy of being discussed. However, our goal was to determine the risk of EOC due to endometriosis in Taiwanese women. Therefore, a surgico-pathological procedure, which is a "gold-standard" tool to diagnose endometriosis [40], should be performed. The IR of EOC in the women either with or without endometriosis was relatively evenly distributed in their own group, and the EOC IR of the women with endometriosis was always higher than that of the women without, contributing to a consistently and persistently higher risk of EOC in the women with endometriosis than in the women without, regardless of the interval of follow-up $(p=1.000)$. In addition, after excluding EOC cases during the first-year follow-up, the median time between enrolment and occurrence of EOC in both groups was similar, without a statistically significant difference (1296 vs. 1402 days, $p=0.8979$ ), suggesting that the increased risk of EOC in women with a new surgico-pathological diagnosis of endometriosis may be irrelevant to surgery. All this suggested that endometriosis itself had a strong association with EOC, not only for a synchronous tumor (EOC arising from endometriosis), but also for any newly developed EOC.

Along with the findings of Kobayashi [1] and Pearce [16], our results supported the lack of an association between follow-up time and risk of EOC. There was no statistically significant difference in the frequency of visits to gynecologists between women with and without endometriosis during the follow-up period (8.9 vs. 9.1 visits, $p=0.6881$ ), which further supported the likelihood that the increased risk of EOC in women with endometriosis might not be biased by surveillance. Our abovementioned results did not support the findings in Melin's [9] and Brinton's reports [4,7] showing the existence of an increased risk of EOC as follow-up time increased (HR of 1.43 increased to 2.23) [9].

Investigating the contribution of age to the association between endometriosis and EOC was another of this study's strengths. The risk of EOC was found to increase with the increase in age at diagnosis of ovarian endometrioma [1]. Women above 50 years of age had a higher HR of 13.2 (95\% CI 6.90-20.9) [1]; Melin and colleagues had a similar finding [9]. Our study findings supported these previously published data. The absolute EOC IR of women with endometriosis consistently and persistently increased with increasing age (from the lowest IR of 4.99 per 10,000 person-years in women aged $<30$ years to the highest IR of 35.81 person-years in women aged $\geq 50$ years). Using women with endometriosis $<30$ years old as a reference to perform risk estimation, we found that women with endometriosis aged $\geq 50$ years had a statistically significantly increased risk of EOC (adjust HR 4.97, 95\% CI 1.03-24.09, $p=0.0465)$.
There were some limitations in our current study. First, we excluded women who had endometriosis diagnosed before the year 2000, and of the most importance, only women who had a surgico-pathological diagnosis of endometriosis were enrolled into the study. Therefore, some women who may have had endometriosis were excluded from this study, due to the absence of a surgico-pathological confirmation. In addition, as shown above, these women may have undergone unilateral salpingo-oophorectomy or radical surgical excision of all visible endometriosis, which might have decreased the risk of EOC [11]. Second, we excluded women with a possibly high or low risk of EOC. For example, women who never visited a gynecologist were excluded in our original design.

Third, we did not evaluate how many women regardless of endometriosis status had visited physicians for antenatal check-up or for pill refills during the study period. In addition, we did not investigate the yes/no and time course of the use of oral pills, which might have had a protective effect against the occurrence of EOC, and the protection might have been stronger in those women with long-term use [14,39]. It is reasonable to suppose that women with endometriosis might have a more pronounced trend and longer interval in the use of pills for symptom control [41]. However, we used the following strategies, including (1) the exclusion of women without a gynecologist visit; and (2) a 1:4 match by obstetric history and frequency of gynecological/obstetric providers' outpatient visits. Both might minimize the potential biases of surveillance or the frequency of medical care. We believed that the frequency of antenatal check-up and/or health consultation would be similar between both groups.

Fourth, we did not investigate the main symptoms of the women seeking gynecologic services. Some of them might have presented with persistent symptoms, which might overestimate the risk. And, some of them might have already had a co-existing EOC, which might further overestimate the risk of EOC in women with endometriosis. The inherent main symptoms of the women with and without endometriosis visiting gynecologists might be different. For example, women with endometriosis might frequently have complaints of dysmenorrhea and abdominal pain. Our data also showed the significant difference in baseline characteristics in both groups. The women with endometriosis had higher rates of comorbid PID, infertility, CVD, DM, CLD, and RD than the women without (Table 1). However, after adjustment of all confounders, the adjusted HR was even higher than the crude HR. Finally, the EOC IR of women without endometriosis was similar to that of the database of the National Cancer Registration System [31]. All of this supported the existence of an actual risk of developing EOC among women with a new surgicopathological diagnosis of endometriosis. 


\section{Conclusions}

Although many uncertainties could not be totally avoided in our current study, our findings corroborate a previously reported association between endometriosis and an increased risk of EOC. The risk of EOC in women with a new surgico-pathological diagnosis of endometriosis was consistently and persistently higher than that in women without endometriosis, regardless of age and follow-up period, and the risk was particularly high in the older population ( $\geq 50$ years). This population group was apparently at risk of EOC because of their higher incidence rate in absolute terms and comparably higher risk of EOC than that of age-matched women without endometriosis and/ or younger women with endometriosis. Active and intensive surgical intervention should be considered with these older women with endometriosis if they do not have other contraindications for surgery.

\section{Competing interests}

The authors declare that they have no competing interests.

\section{Authors' contributions}

KC Wang and WH Chang contributed equally to this work. KC Wang designed the study, analyzed the data and helped to draft the manuscript.

WH Chang designed the study, analyzed the data, and helped to draft the manuscript. WL Lee participated in the design the study and helped to revise the draft. N Huang and HY Huang helped to analyze the data. MS Yen helped to revise the draft. CY Guo helped to design the study, analyze the data and revise the draft, and supervised research. PH Wang designed the study, analyzed the data, interpreted the data, drafted the manuscript, edited the paper and supervised research. All authors read and approved the final manuscript.

\begin{abstract}
Acknowledgements
Supported by grants from the Ministry of Science and Technology, Executive Yuan (NSC 102-2314-B-010-032; NSC 99-2314-B-010-009-MY3; MOST 103-2314-B010 -043 -MY3 to P.-H. Wang and NSC100-2314-B-010-057-MY2 to C.-Y. Guo), Taipei Veterans General Hospital (V102C-141; V103C-112; V102E4-003; V103E4-003 to P.-H. Wang, and V103A-016 to W.-H. Chang) and the Foundation of Cheng-Hsin General Hospital (CHGH 101-18 to W.-L. Lee). The funders had no role in study design, data collection and analysis, decision to publish, or preparation of the manuscript. No additional external funding was received for this study. We thank Y.J. Chou, MD., Ph.D., for his valuable participation in data management and analyses. This study is based in part on data from the National Health Insurance Research Database provided by the Bureau of National Health Insurance, Department of Health and managed by National Health Research Institutes. We also thank the Medical Science \& Technology Building of Taipei Veterans General Hospital for providing experimental space and facilities.
\end{abstract}

\section{Author details}

${ }^{1}$ Department of Nursing, Oriental Institute of Technology, New Taipei City, Taiwan. ${ }^{2}$ Department of Nursing, Taipei Veterans General Hospital, Taipei, Taiwan. ${ }^{3}$ Department of Nursing, National Yang-Ming University School of Nursing, Taipei, Taiwan. ${ }^{4}$ Institute of Public Health, and Institute of Hospital and Health Care Administration, National Yang-Ming University, Taipei, Taiwan. ${ }^{5}$ Division of Gynecology, Taipei Veterans General Hospital, Taipei, Taiwan. ${ }^{6}$ Department of Medicine, Cheng-Hsin General Hospital, Taipei, Taiwan. ${ }^{7}$ Department of Obstetrics and Gynecology, National Yang-Ming University, Taipei, Taiwan. ${ }^{8}$ Biostatics Task Force, Taipei Veterans General Hospital, Taipei, Taiwan. ${ }^{9}$ Department of Medical Research, China Medical University Hospital, Taichung, Taiwan. ${ }^{10}$ Immunology Center, Taipei Veterans General Hospital, Taipei, Taiwan. ${ }^{11}$ Division of Gynecology, Taipei Veterans General Hospital and Department of Obstetrics and Gynecology, National Yang-Ming University School of Medicine, 201, Section 2, Shih-Pai Road, Taipei 112, Taiwan.
Received: 10 August 2014 Accepted: 3 November 2014

Published: 18 November 2014

\section{References}

1. Kobayashi H, Sumimoto K, Kitanaka T, Yamada Y, Sado T, Sakata M, Yoshida S, Kawaguchi R, Kanayama S, Shigetomi H, Haruta S, Tsuji Y, Ueda S, Terao T: Ovarian endometrioma-risks factors of ovarian cancer development. Eur J Obstet Gynecol Reprod Biol 2008, 138:187-93.

2. Aris A: Endometriosis-associated ovarian cancer: a ten-year cohort study of women living in the Estrie Region of Quebec, Canada. J Ovarian Res 2010, 3:2.

3. Borgfeldt C, Andolf E: Cancer risk after hospital discharge diagnosis of benign ovarian cysts and endometriosis. Acta Obstet Gynecol Scand 2004 83:395-400

4. Brinton LA, Gridley G, Persson I, Baron J, Bergqvist A: Cancer risk after a hospital discharge diagnosis of endometriosis. Am J Obstet Gynecol 1997, 176:572-579.

5. Brinton LA, Lamb EJ, Moghissi KS, Scoccia B, Althuis MD, Mabie JE, Westhoff $\mathrm{CL}$ : Ovarian cancer risk associated with varying causes of infertility. Fertil Steril 2004, 82:405-414.

6. Brinton LA, Westhoff CL, Scoccia B, Lamb EJ, Trabert B, Niwa S, Moghissi KS: Causes of infertility as predictors of subsequent cancer risk. Epidemiology 2005, 16:500-507.

7. Brinton LA, Sakoda LC, Sherman ME, Frederiksen K, Kjaer SK, Graubard BI, Olsen $\mathrm{JH}$, Mellemkjaer L: Relationship of benign gynecologic diseases to subsequent risk of ovarian and uterine tumors. Cancer Epidemiol Biomarkers Prev 2005, 14:2929-2935.

8. Kotsopoulos J, Terry KL, Poole EM, Rosner B, Murphy MA, Hecht JL, Crum CP, Missmer SA, Cramer DW, Tworoger SS: Ovarian cancer risk factors by tumor dominance, a surrogate for cell of origin. Int J Cancer 2013, 133:730-739.

9. Melin A, Sparen P, Persson I, Bergqvist A: Endometriosis and the risk of cancer with special emphasis on ovarian cancer. Hum Reprod 2006, 21:1237-1242.

10. Melin A, Sparén P, Bergqvist A: The risk of cancer and the role of parity among women with endometriosis. Hum Reprod 2007, 22:3021-3026.

11. Melin AS, Lundholm C, Malki N, Swahn ML, Sparèn P, Bergqvist A: Hormonal and surgical treatments for endometriosis and risk of epithelial ovarian cancer. Acta Obstet Gynecol Scand 2013, 92:546-554.

12. Merritt MA, Green AC, Nagle CM, Webb PM, Australian Cancer Study (Ovarian Cancer); Australian Ovarian Cancer Study Group: Talcum powder, chronic pelvic inflammation and NSAIDs in relation to risk of epithelial ovarian cancer. Int J Cancer 2008, 122:170-176.

13. Merritt MA, De Pari M, Vitonis AF, Titus LJ, Cramer DW, Terry KL: Reproductive characteristics in relation to ovarian cancer risk by histologic pathways. Hum Reprod 2013, 28:1406-1417.

14. Modugno F, Ness RB, Allen GO, Schildkraut JM, Davis FG, Goodman MT: Oral contraceptive use, reproductive history, and risk of epithelial ovarian cancer in women with and without endometriosis. Am J Obstet Gynecol 2004, 191:733-740.

15. Olson JE, Cerhan JR, Janney CA, Anderson KE, Vachon CM, Sellers TA: Postmenopausal cancer risk after self-reported endometriosis diagnosis in the lowa Women's Health Study. Cancer 2002, 94:1612-1618.

16. Pearce CL, Templeman C, Rossing MA, Lee A, Near AM, Webb PM, Nagle CM, Doherty JA, Cushing-Haugen KL, Wicklund KG, Chang-Claude J, Hein R Lurie G, Wilkens LR, Carney ME, Goodman MT, Moysich K, Kjaer SK, Hogdall E, Jensen A, Goode EL, Fridley BL, Larson MC, Schildkraut JM, Palmieri RT, Cramer DW, Terry KL, Vitonis AF, Titus $\sqcup$, Ziogas A, et al: Association between endometriosis and risk of histological subtypes of ovarian cancer: a pooled analysis of case-control studies. Lancet Oncol 2012, 13:385-394.

17. Pearce CL, Rossing MA, Lee AW, Ness RB, Webb PM, Australian Cancer Study (Ovarian Cancer); Australian Ovarian Cancer Study Group, Chenevix-Trench G, Jordan SM, Stram DA, Chang-Claude J, Hein R, Nickels S, Lurie G, Thompson PJ, Carney ME, Goodman MT, Moysich K, Hogdall E, Jensen A, Goode EL, Fridley BL, Cunningham JM, Vierkant RA, Weber RP, Ziogas A, Anton-Culver H, Gayther SA, Gentry-Maharaj A, Menon U, Ramus SJ, et al: Combined and interactive effects of environmental and GWAS-identified risk factors in ovarian cancer. Cancer Epidemiol Biomarkers Prev 2013, 22:880-890.

18. Rossing MA, Daling JR, Weiss NS, Moore DE, Self SG: Ovarian tumors in a cohort of infertile women. N Engl J Med 1994, 331:771-776.

19. Rossing MA, Cushing-Haugen KL, Wicklund KG, Doherty JA, Weiss NS: Risk of epithelial ovarian cancer in relation to benign ovarian conditions and ovarian surgery. Cancer Causes Control 2008, 19:1357-1364. 
20. Stewart LM, Holman CD, Aboagye-Sarfo P, Finn JC, Preen DB, Hart R: In vitro fertilization, endometriosis, nulliparity and ovarian cancer risk. Gynecol Oncol 2013, 128:260-264

21. Venn A, Watson L, Lumley J, Giles G, King C, Healy D: Breast and ovarian cancer incidence after infertility and in vitro fertilisation. Lancet 1995, 346:995-1000.

22. Buis CC, Van Leeuwen FE, Mooij TM, Burger CW, OMEGA Project Group: Increased risk for ovarian cancer and borderline ovarian tumours in subfertile women with endometriosis. Hum Reprod 2013, 28:3358-3369.

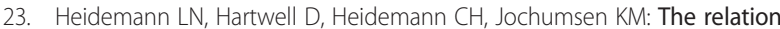
between endometriosis and ovarian cancer - a review. Acta Obstet Gynecol Scand 2014, 93:20-31.

24. Scarfone G, Bergamini A, Noli S, Villa A, Cipriani S, Taccagni G, Vigano' P, Candiani M, Parazzini F, Mangili G: Characteristics of clear cell ovarian cancer arising from endometriosis: a two center cohort study. Gynecol Oncol 2014, 133:480-484.

25. Kim HS, Kim TH, Chung HH, Song YS: Risk and prognosis of ovarian cancer in women with endometriosis: a meta-analysis. Br J Cancer 2014, 110:1878-1890.

26. Rothwell PM: Treating individuals 2 . Subgroup analysis in randomised controlled trials: importance, indications, and interpretation. Lancet 2005, 365:176-186.

27. Papathanasiou A: Implementing the ESHRE 'poor responder' criteria in research studies: methodological implications. Hum Reprod 2014, 29:1835-1838.

28. Wang PH, Chang YH, Yang YH, Chang WH, Huang SY, Lai CR, Juang CM, Chen YJ, Horng HC, Wen KC, Ng HT, Yuan CC, Chao KC, Yen MS: Outcome of patients with bulky IB $(\geq 6 \mathrm{~cm})$ cervical squamous cell carcinoma with and without cisplatin-based neoadjuvant chemotherapy. Taiwan J Obstet Gynecol 2014, 53:330-336.

29. Yang $M H$, Wang PH, Wang SJ, Sun WZ, Oyang YJ, Fuh JL: Women with endometriosis are more likely to suffer from migraines: a populationbased study. PLoS One 2012, 7:e33941.

30. Jou HJ, Siao RY, Tsai YS, Chen YT, Li CY, Chen CC: Postdischarge rehospitalization and in-hospital mortality among Taiwanese women with hip fracture. Taiwan J Obstet Gynecol 2014, 53:43-47.

31. Chiang YC, Chen CA, Chiang CJ, Hsu TH, Lin MC, You SL, Cheng WF, Lai MS: Trends in incidence and survival outcome of epithelial ovarian cancer: 30-year national population-based registry in Taiwan. J Gynecol Oncol 2013, 24:342-351.

32. Köbel M, Kalloger SE, Baker PM, Ewanowich CA, Arseneau J, Zherebitskiy V, Abdulkarim S, Leung S, Duggan MA, Fontaine D, Parker R, Huntsman DG, Gilks CB: Diagnosis of ovarian carcinoma cell type is highly reproducible: a transcanadian study. Am J Surg Pathol 2010, 34:984-993.

33. Lin DY, Wei $L$ : The robust inference for the proportional hazards model. J Am Stat Assoc 1989, 84:1074-1078.

34. Koshiyama M, Matsumura N, Konishi I: Recent concepts of ovarian carcinogenesis: type I and type II. Biomed Res Int 2014, 2014:934261.

35. Nezhat FR, Pejovic T, Reis FM, Guo SW: The link between endometriosis and ovarian cancer: clinical implications. Int J Gynecol Cancer 2014 24:623-628.

36. Van Gorp T, Amant F, Neven P, Vergote I: Endometriosis and the development of malignant tumours of the pelvis. A review of literature. Best Pract Res Clin Obstet Gynaecol 2004, 18:349-371.

37. Tay SK, Cheong MA: Evidence for ethnic and environmental contributions to frequency of ovarian clear cell carcinoma. Aust N Z J Obstet Gynaecol 2014, 54:225-230.

38. Vercellini P, Somigliana E, Buggio L: Endometriosis and ovarian cancer. Lancet Oncol 2012, 13:e188-e189.

39. Rice MS, Murphy MA, Vitonis AF, Cramer DW, Titus LJ, Tworoger SS, Terry KL: Tubal ligation, hysterectomy and epithelial ovarian cancer in the New England case-control study. Int J Cancer 2013, 133:2415-2421.
40. Lai CR, Hsu CY, Chen YJ, Yen MS, Chao KC, Li AF: Ovarian cancers arising from endometriosis: a microenvironmental biomarker study including ER, HNF1ß, p53, PTEN, BAF250a, and COX-2. J Chin Med Assoc 2013, 76:629-634.

41. Horng HC, Chen $\mathrm{CH}$, Chen CY, Tsui KH, Liu WM, Wang PH, Chang WH, Huang BS, Sun HD, Chang TC, Chang WC, Yen MS: Uterine-sparing surgery for adenomyosis and/or adenomyoma. Taiwan J Obstet Gynecol 2014, 53:3-7.

doi:10.1186/1471-2407-14-831

Cite this article as: Wang et al:: An increased risk of epithelial ovarian cancer in Taiwanese women with a new surgico-pathological diagnosis of endometriosis. BMC Cancer 2014 14:831.

\section{Submit your next manuscript to BioMed Central and take full advantage of:}

- Convenient online submission

- Thorough peer review

- No space constraints or color figure charges

- Immediate publication on acceptance

- Inclusion in PubMed, CAS, Scopus and Google Scholar

- Research which is freely available for redistribution

Submit your manuscript at www.biomedcentral.com/submit
C Biomed Central 